\title{
Food Additives in the European Union: Changes in their Evaluation and Regulation
}

\section{Luetzow M}

sa.qual Regulatory Affairs Services GmbH, Feldhofweg 38, 5432 Neuenhof, Switzerland, EMail:maluetzow@saqual.com

\section{Abstract}

In the European Union, the framework for the evaluation and pre-market approval of food additives is undergoing significant changes. Whereas responsibility for the risk assessment of food chemicals was given to European Food Safety Authority (EFSA), new legislation shall give the European Commission implementation power for food additive regulations.

\section{Introduction and early history}

The presence of food additives in the daily diet continues to be of concern to many consumers and their concern will probably not disappear as long as substances are added to food in order to modify their properties. One functional class of food additives, the colours, were the object of the first piece of harmonized European food legislation back in 1962: governments of the six founding countries of the European Communities wanted to show consumers that this new political entity would affect their life positively by ensuring safer food. This first Directive on food colours established a positive list of safe compounds at European level (a principle extended to other food additive classes), however, permitted use levels in specific foods were regulated mainly at the national level. In the first years no dedicated European scientific body assessed the safety of food additives; the corresponding work of the Joint FAO/WHO Expert Committee on Food Additives (JECFA) which started in 1956 was recognized and JECFA's opinions continued to be respected also by the Scientific Committee for Food (SCF) which was founded in 1974.

\section{Current regulatory framework}

Following the political decision to create a single barrier-free European market for goods, a harmonized European regulatory environment became also essential for all foods and food additives - between 1989 and 1995 comprehensive new food additive legislation was drafted, adopted and subsequently enforced which included also harmonized pan-European conditions of use. A probably unique feature of this legislation if compared to food additive regulations from other countries is that all additives and every single use level of an additive in a food are subject to discussion and vote not only by the European Commission, the governments of the 25 member states for the European Union (EU), but also by the members of the European Parliament.

\section{Food scares and international trade in foods}

BSE, antimicrobial resistance, dioxins, growth hormones are just some of the food scares or "scandals" of the past ten, fifteen years; they received more immediate attention at international level due to the increased global trade in food commodities and processed, i.e. ready to eat foods. It is not a coincidence that such alerts became more "global" after the foundation of the World Trade Organization in 1995 which foresaw an increased role of the FAO/WHO sponsored Codex Alimentarius as an international reference body for health-based food standards. New and stricter rules for rejecting imports of food products as laid down in the Sanitary and Phytosanitary Measures Agreement (SPS) triggered directly or indirectly in many countries major changes of food legislation and significant reorganisations of food control. The European Commission and EU member states responded to these challenges by a new food law which was adopted in the aftermath of the BSE crisis in 2002. One central element of this framework was the foundation of a new independent scientific point of reference in 
risk assessment, the European Food Safety Authority (EFSA). The functional separation between risk managers and risk assessors as requested by the risk analysis principles of the Codex Alimentarius is now balanced within the European Union between the European Commission (Brussels, Belgium) and EFSA (Parma, Italy).

\section{The AFC Panel}

EFSA continues with the Commission's previous approach that the scientific advice on food safety shall be given by committees consisting of well-acknowledged and independent experts. In that sense EFSA is merely providing resources, infrastructure and means of communication, the risk assessment itself is not the task of its staff. The assessment of food additives is since 2003 the responsibility of the Panel on food additives, flavourings, processing aids and materials in contact with food (AFC) which continues the corresponding work of the former Scientific Committee for Food. The AFC panel receives applications for evaluations and questions related to the safety of food additives from the European Commission in Brussels and sometimes from members states only; the current and also future procedures do not foresee direct submissions from industry.

\section{Pending proposal for new food additive legislation}

The current approval process for food additives involves many institutions and became even more complex with the additional role EFSA plays in it; the main objective of the new food additive framework regulation to be proposed soon by the Commission is to "simplify food additive legislation by creating a single instrument for principles, procedures and authorisations". However, more important is the objective to move the power for implementation of food additive legislation from the current "co-decision" approach involving also the European Parliament and the Council of Ministers to one called "comitology" which involves the Commission and regulatory committees (i.e. member states' administrations). Furthermore the role of EFSA and its panels will be established more clearly and confirmed.

\section{Re-evaluation programme for existing food additives}

The new food additive legislation shall also provide a legal framework for the re-evaluation of all existing food additives which were approved until today. EFSA will be asked to perform new risk-assessments for approx. 200 food additives. Following a direct request from the Commission that anticipated the foreseen mandatory legal re-evaluation, EFSA started already this year with the re-evaluation of some food colours which were, for the purpose of the exercise, grouped as "natural" and "synthetic" colours. An external contractor will perform a review of the work done previously by JECFA and SCF, consider the analysis undertaken recently by the Nordic Council, and use any additional new literature, to identify possible data gaps and to determine the need for a more thorough re-evaluation of each colour. The work shall be completed by 2007; the experience gained with this first group of additives will have considerable impact on the re-evaluation of other additives belonging to different functional groups such as sweeteners, preservatives, antioxidants.

\section{References}

European Commission (2005): Draft Working Paper - Regulation of the European Parliament and of the Council on Food Additives. WGA/004/03 rev10. European Commission, Brussels.

Nordic Council (2002): Food additives in Europe 2000 -- Status of safety assessments of food additives presently permitted in the EU. Nordic Council, Copenhagen

Scientific Committee on Food (2001): Guidance on Submissions for Food Additive Evaluations by the Scientific Committee on Food (opinion expressed on 11 July 2001). European Commission, Brussels. 